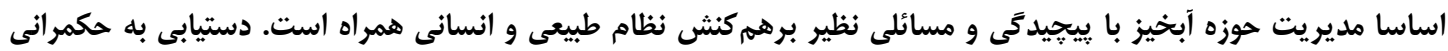

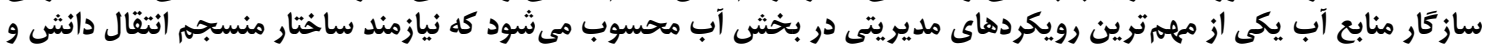

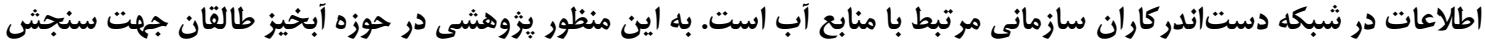

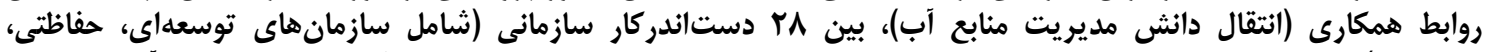

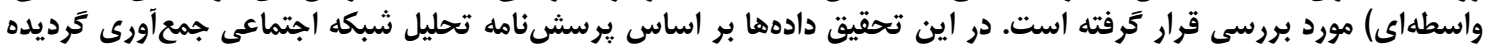

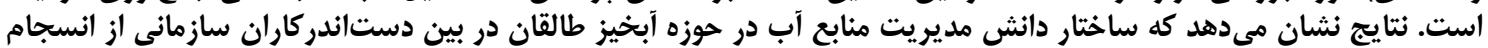

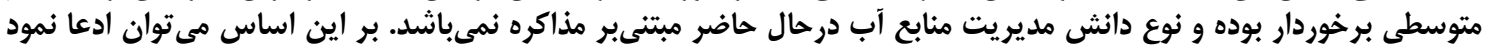

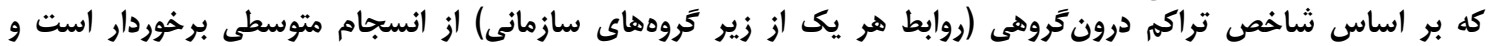

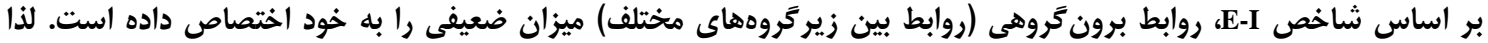

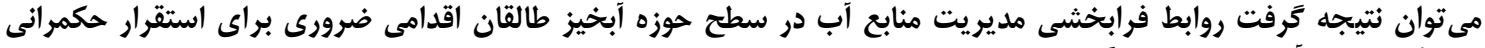
مشاركتى منابع آب محسوب مى متردد.

وازههاى كليدى: حكمرانى آب، تصويرسازى مشترك، سازكارى، دستاندركاران سازمانى، انتقال دانش، تحليل شبكه اجتماعى، طالقان

شيوههاى اجرايى (مديريتى) به بحران اكولوزيكى عصر حاضر

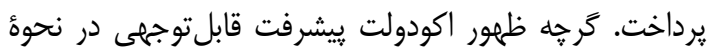

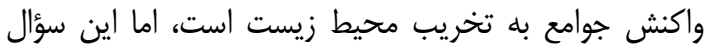

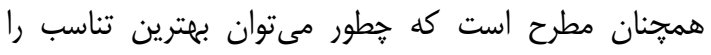

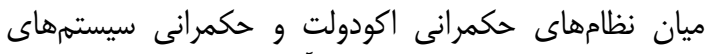

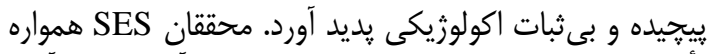

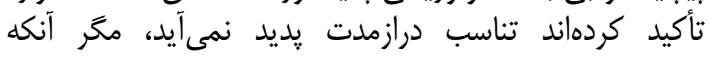

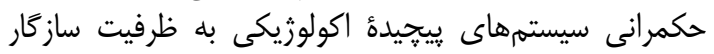

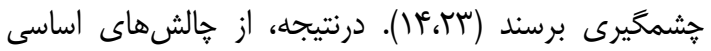

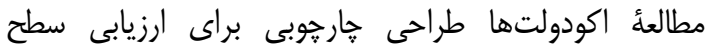

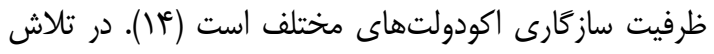

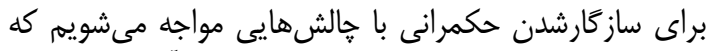

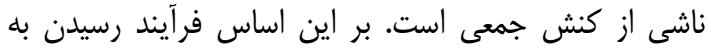

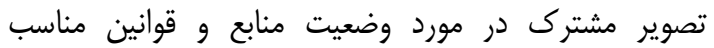

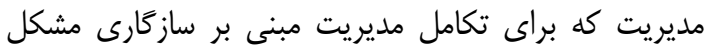

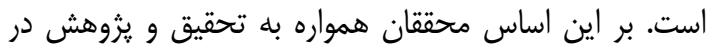

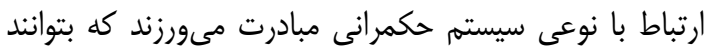

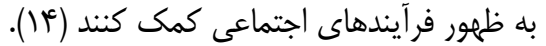

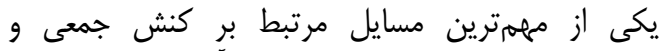

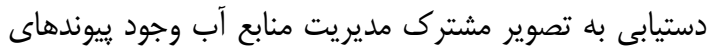

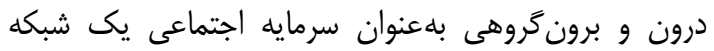

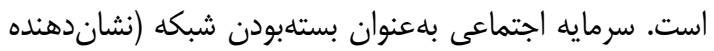

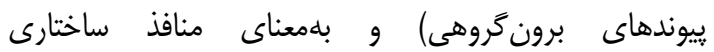

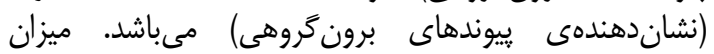
بستهبودن شبكه نشاندهنده ميزان انسجام است و ميزان ميزان
مقدمه - - مقد

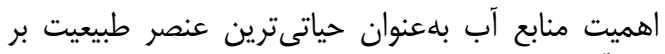

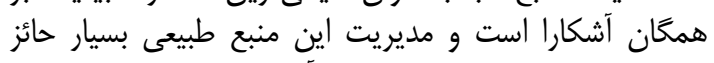

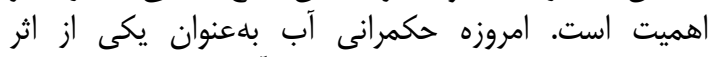

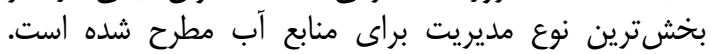

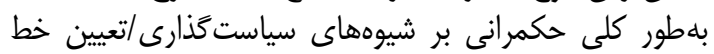

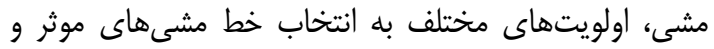

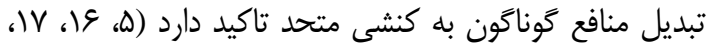

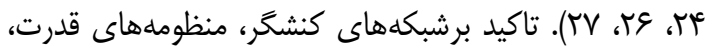

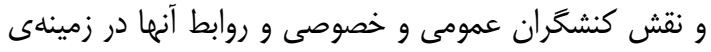

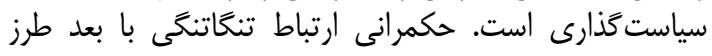

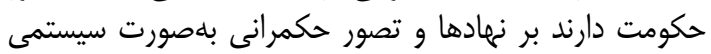

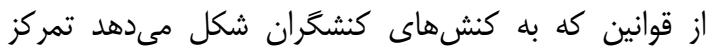

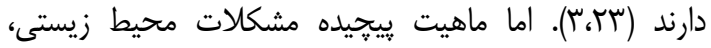

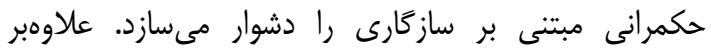

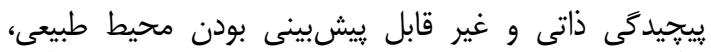

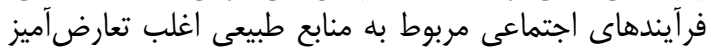

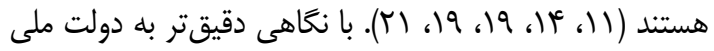

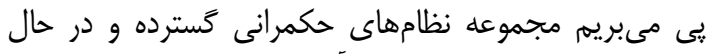

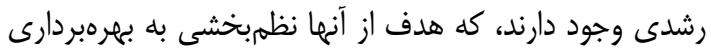

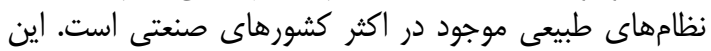

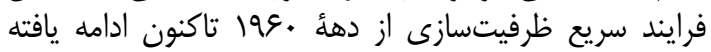

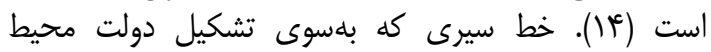

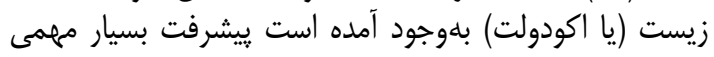

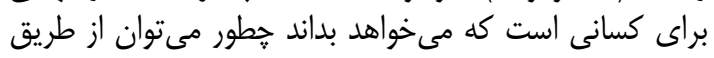


را برعهده دارد. بر اين اساس مديريت منابع آب اين منطقه با

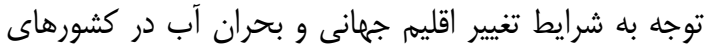

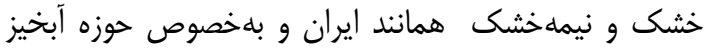

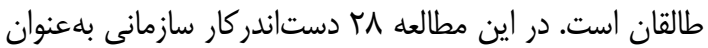

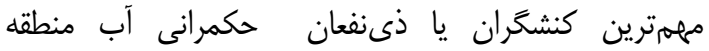

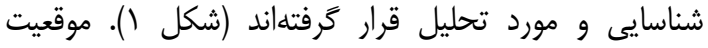

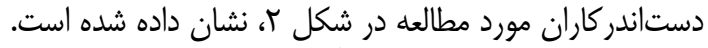

تحليل شبكه اجتماعى (SNA')

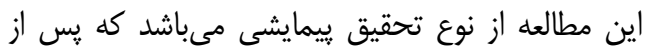

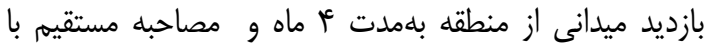

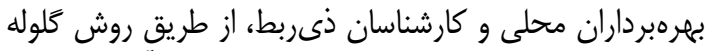

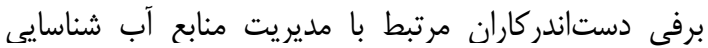

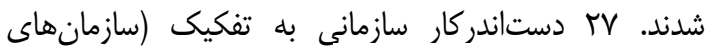

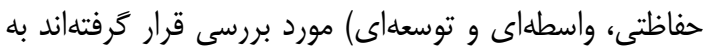

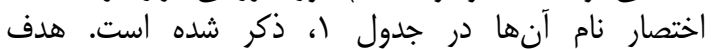

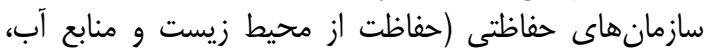

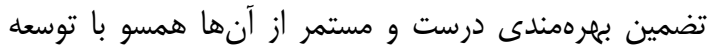

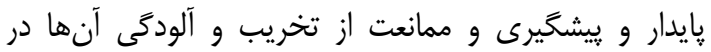

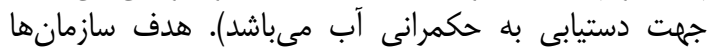

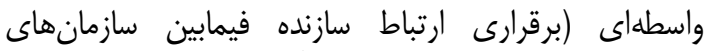

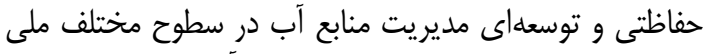

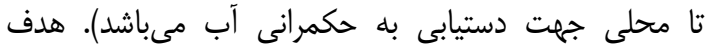

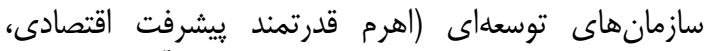

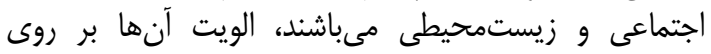

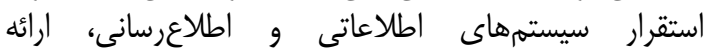

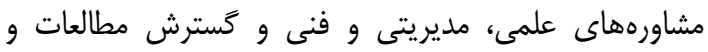

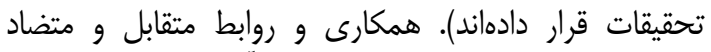

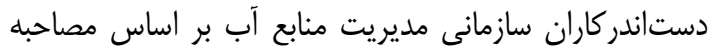

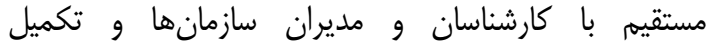

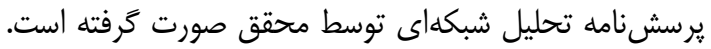

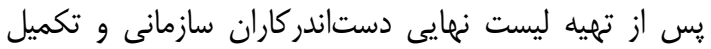

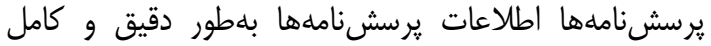

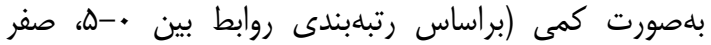

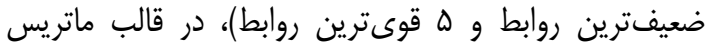

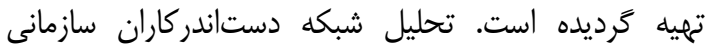

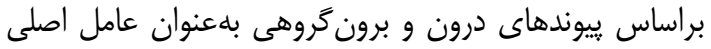

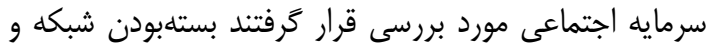

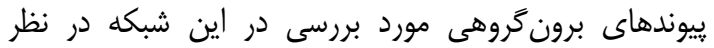

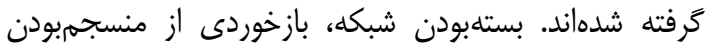

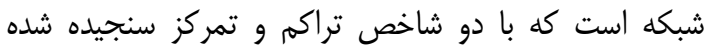

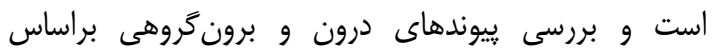

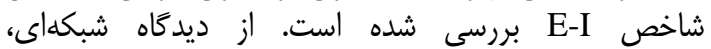

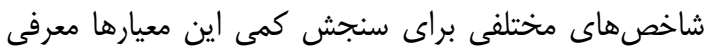

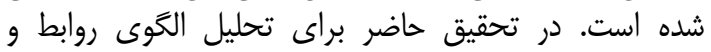

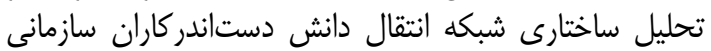

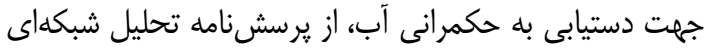

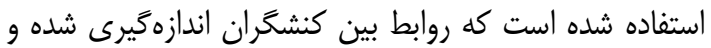

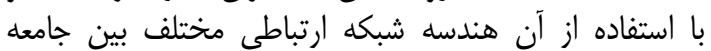
هدف را بيرون كشيد و جايكاه كنشكران را در آن تحليل كرد.

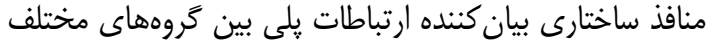

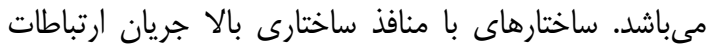

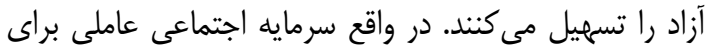

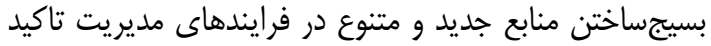

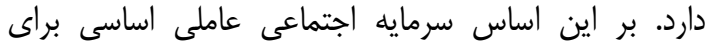

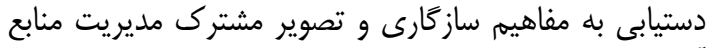

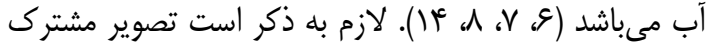

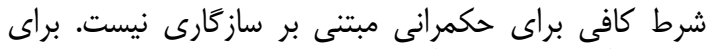

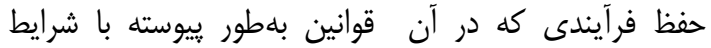

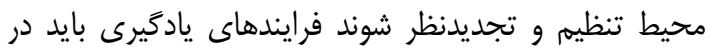

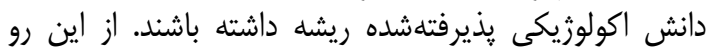

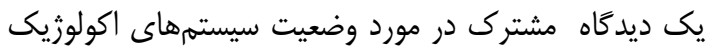

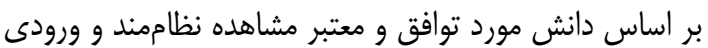

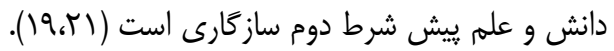

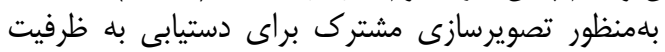

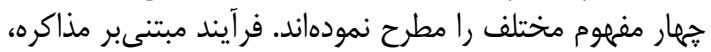

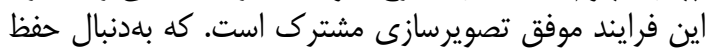

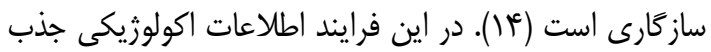

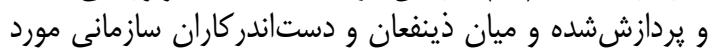

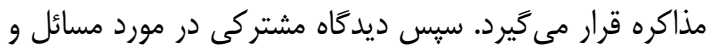

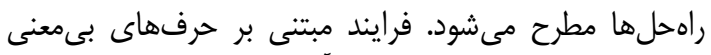

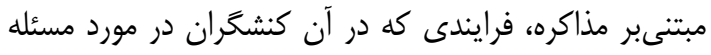

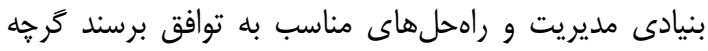

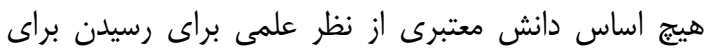

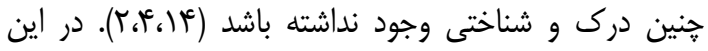

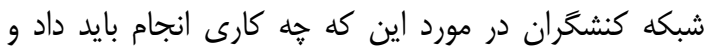

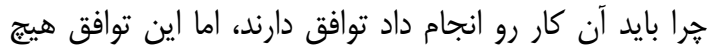

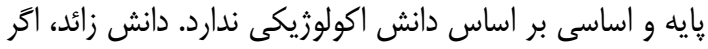

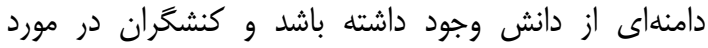
نحوهى توصيف وضعيت اكولوزيك توافق داشت انته باشند اما دان در

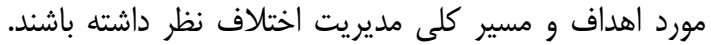

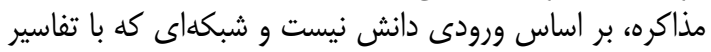

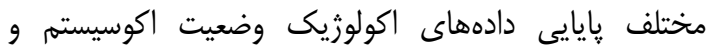

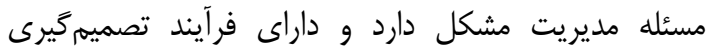

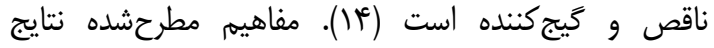

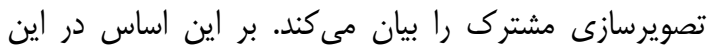

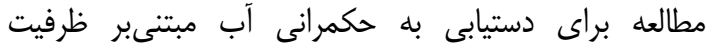

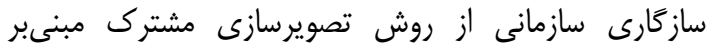

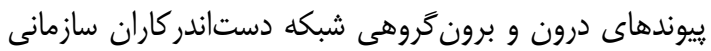
حوزهآبخيز طالقان بهره كرفته شده است.

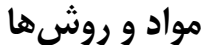 منطقه مورد مطالعه} منطقه مورد مطالعه در اين يزوهش حورة حوزآبخيز طالقان

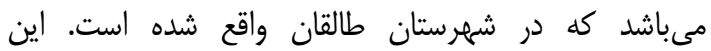

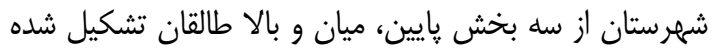

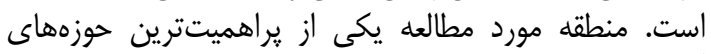

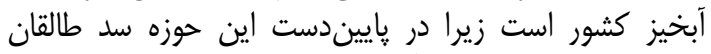
واقع شده است كه تامين آب شرب كلان شهر تهران و قزوين 
كه يكى از برنامهاى خوب و مطرح در اين زمينه UCINET

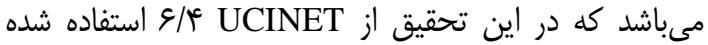
است. در اين تحقيق از شاخصهاى تراكم و و

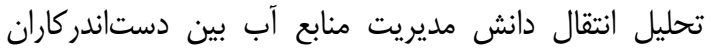

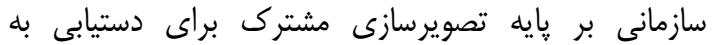

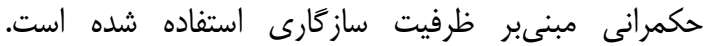

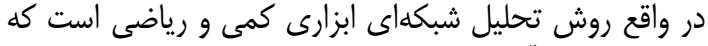

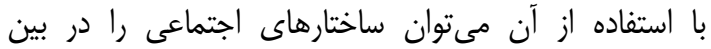

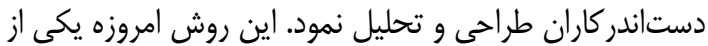

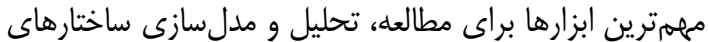

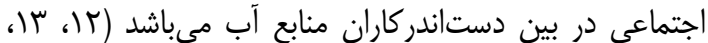

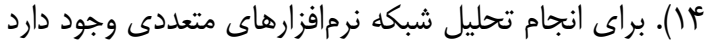

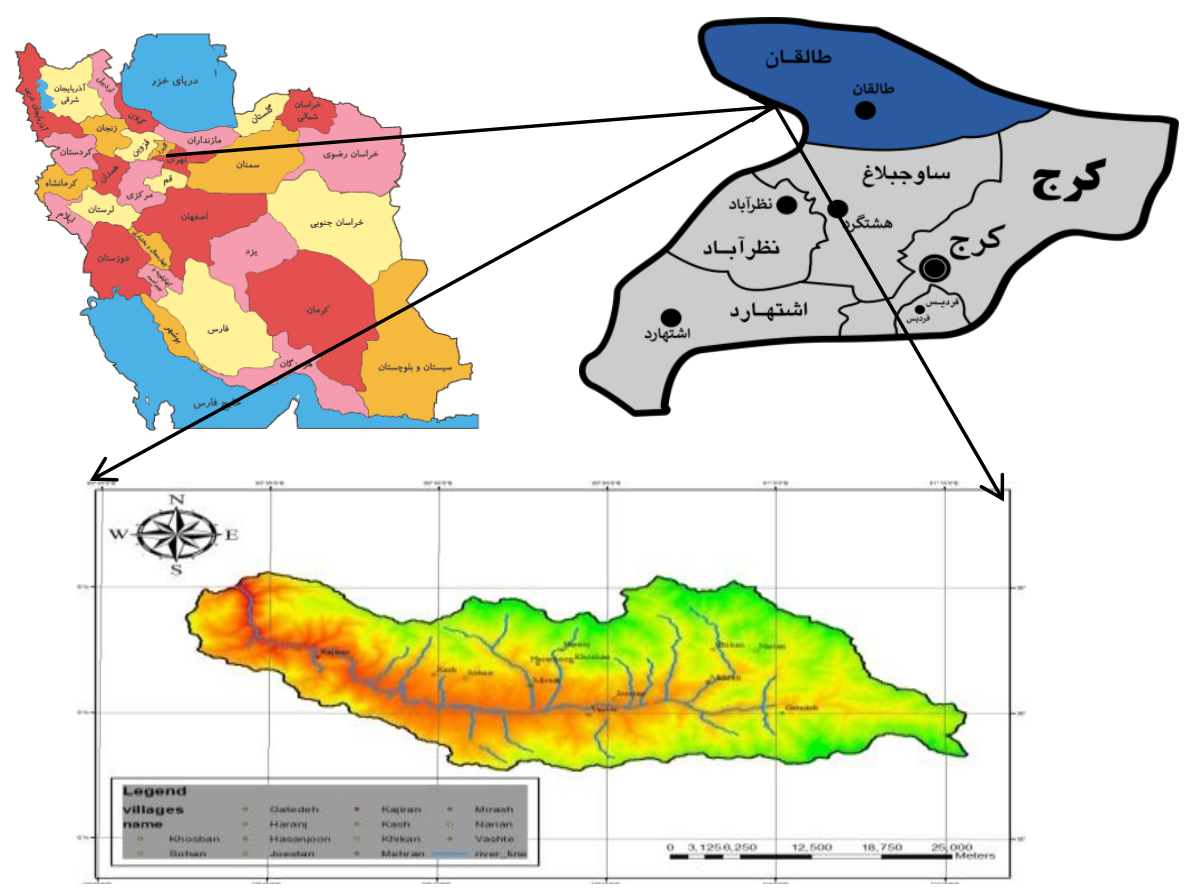

شكل 1- موقعيت جغرافيايى منطقه مورد مطالعه

Figure 1. The geographic location of the study area

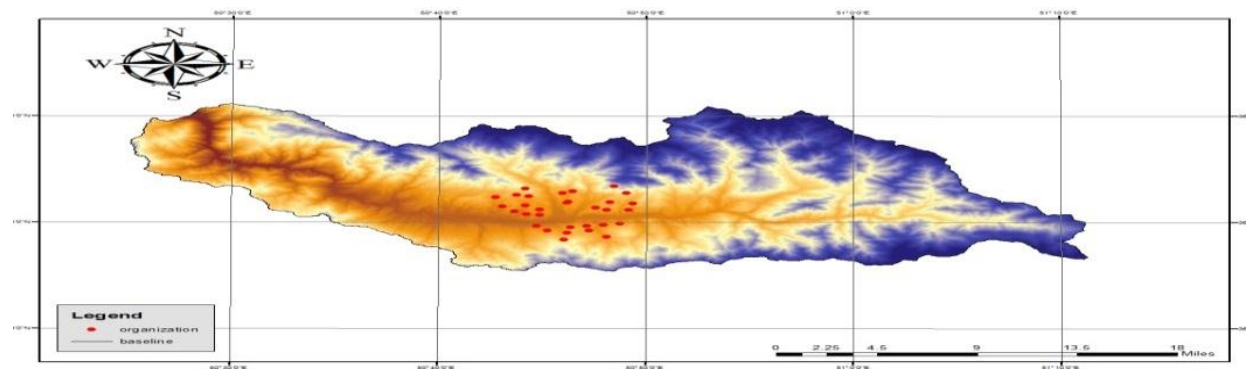

شكل r- موقعيت دستاندر كاران سازمانى حوزه آبخيز طالقان

Figure 2. Shows the organizational position of Taleghan watershed 
Table 1. Effective organizational names of water resources management in Taleghan watershed

\begin{tabular}{|c|c|c|}
\hline سازمان هاى واسطهاى & سازمانهاى توسعهاى & ساز مانهاى حفاظتى \\
\hline 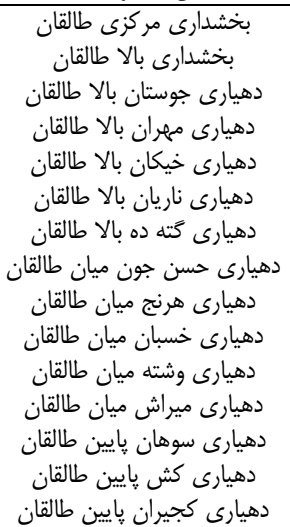 & 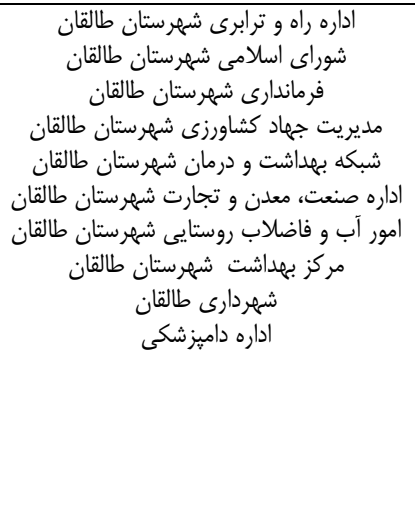 & 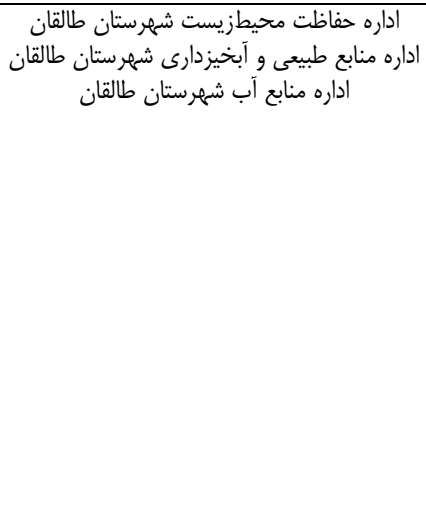 \\
\hline
\end{tabular}

مشكلاتى بسيارى براى استفاده از شاخص تراكم مطرح شده

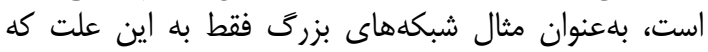

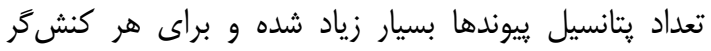

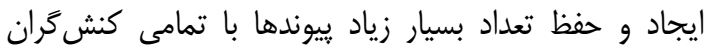

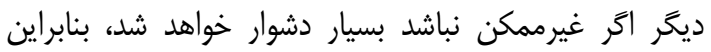

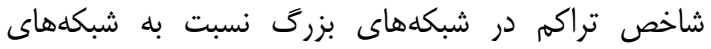

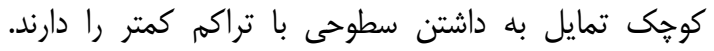

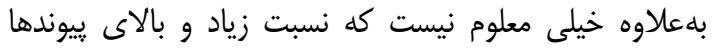

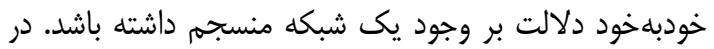

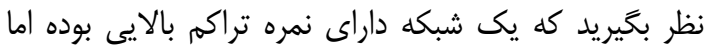

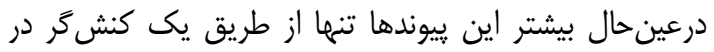

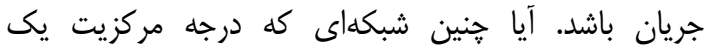
كنشگر بسيار بيشتر از ديخر كنش

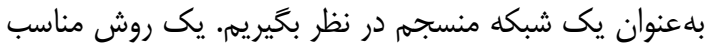

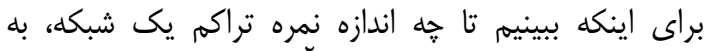

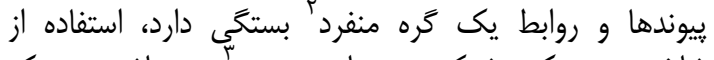

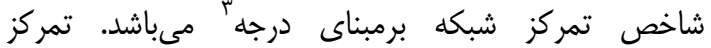

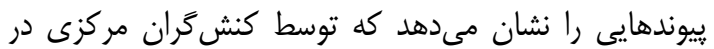

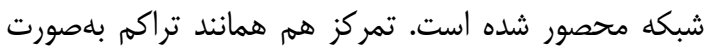

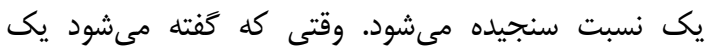

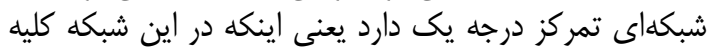

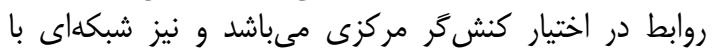

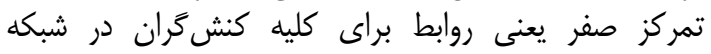

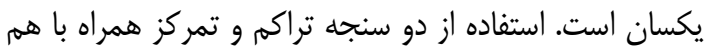

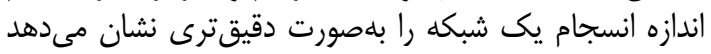

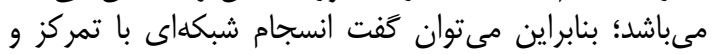

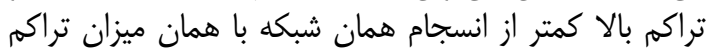

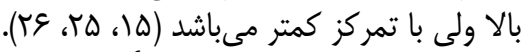

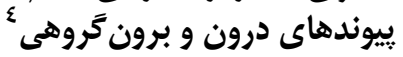

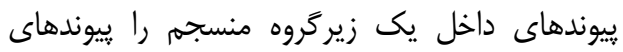

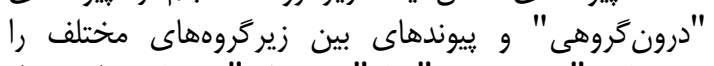

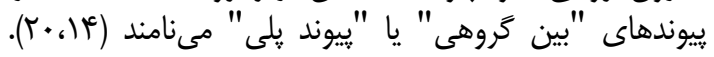

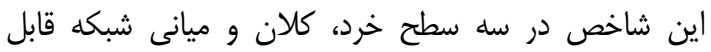

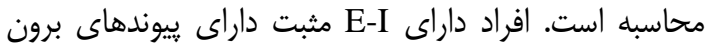

\section{شاخص هاى تحليل شبكه اى

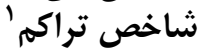
تراكم شاخصى براى سنجش اخت ارتباط مستقيم كنش

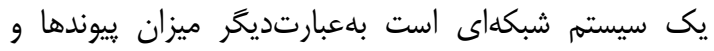

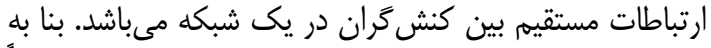

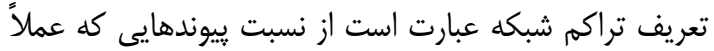

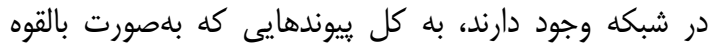

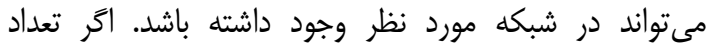

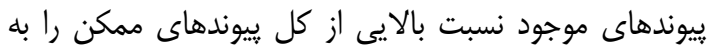

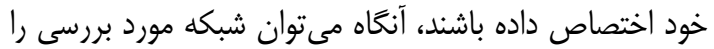

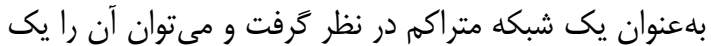

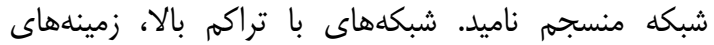

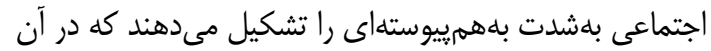

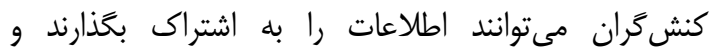

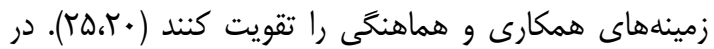

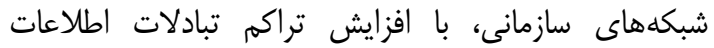

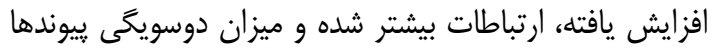

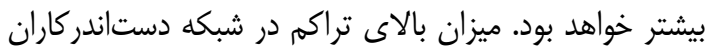

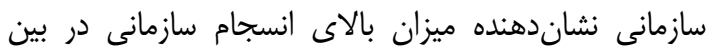

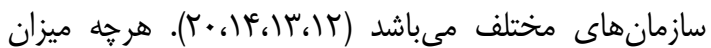

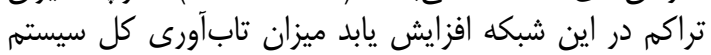

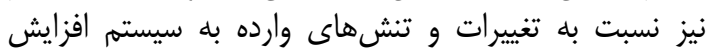

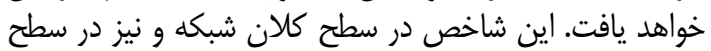

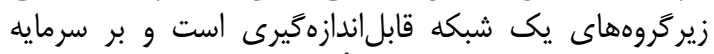

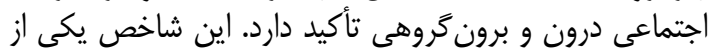

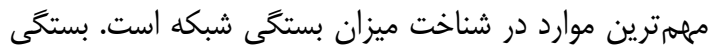

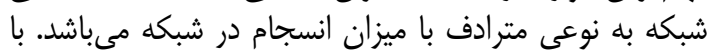

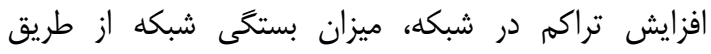

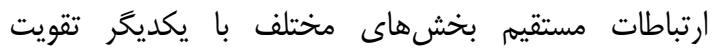

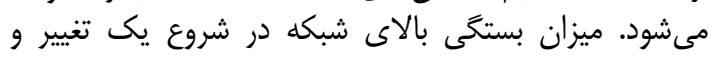

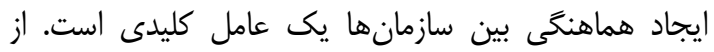

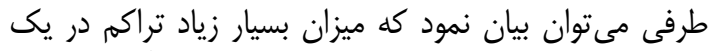

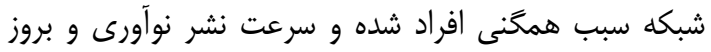

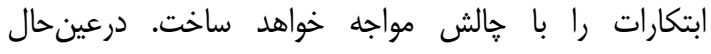




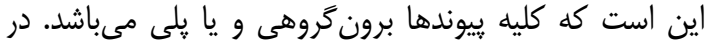

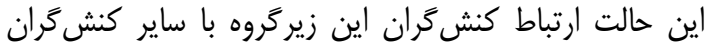

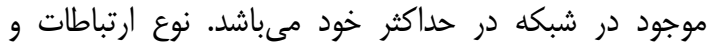

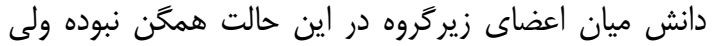

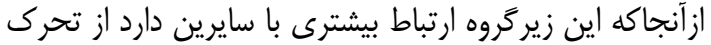

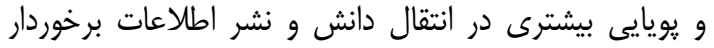

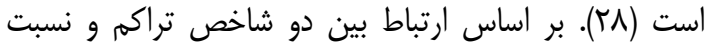

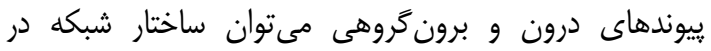
تصويرسازى مشترك را بر اساس شكل، زير مير تشريح كرد

بر اساس اين شكل محور افقى بر اساس بستهبودن

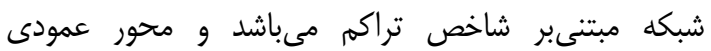

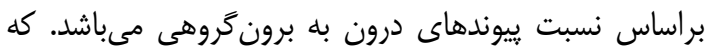

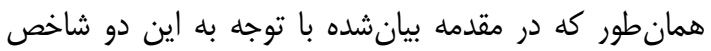

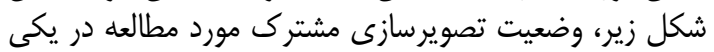

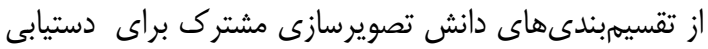
حكمرانى آب قرار مى گيرد.

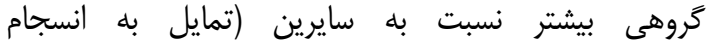

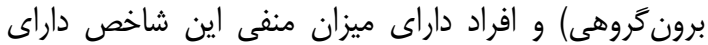

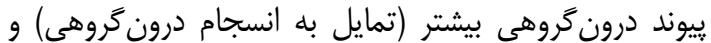

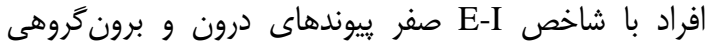

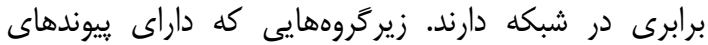

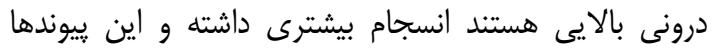

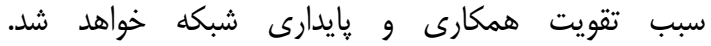

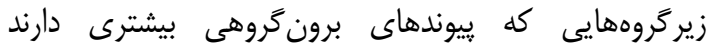

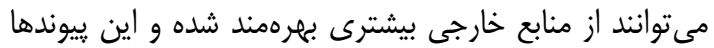

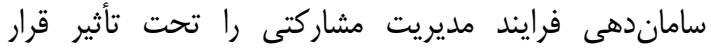

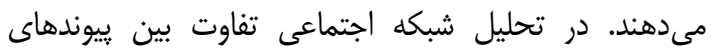

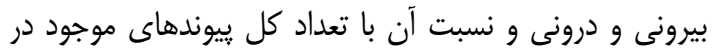

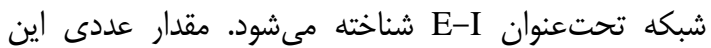

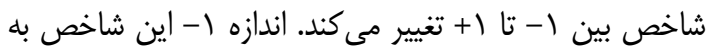

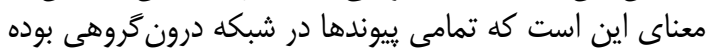

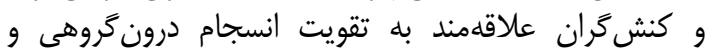

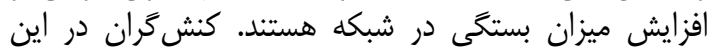

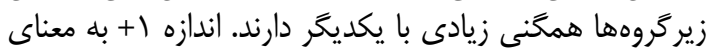

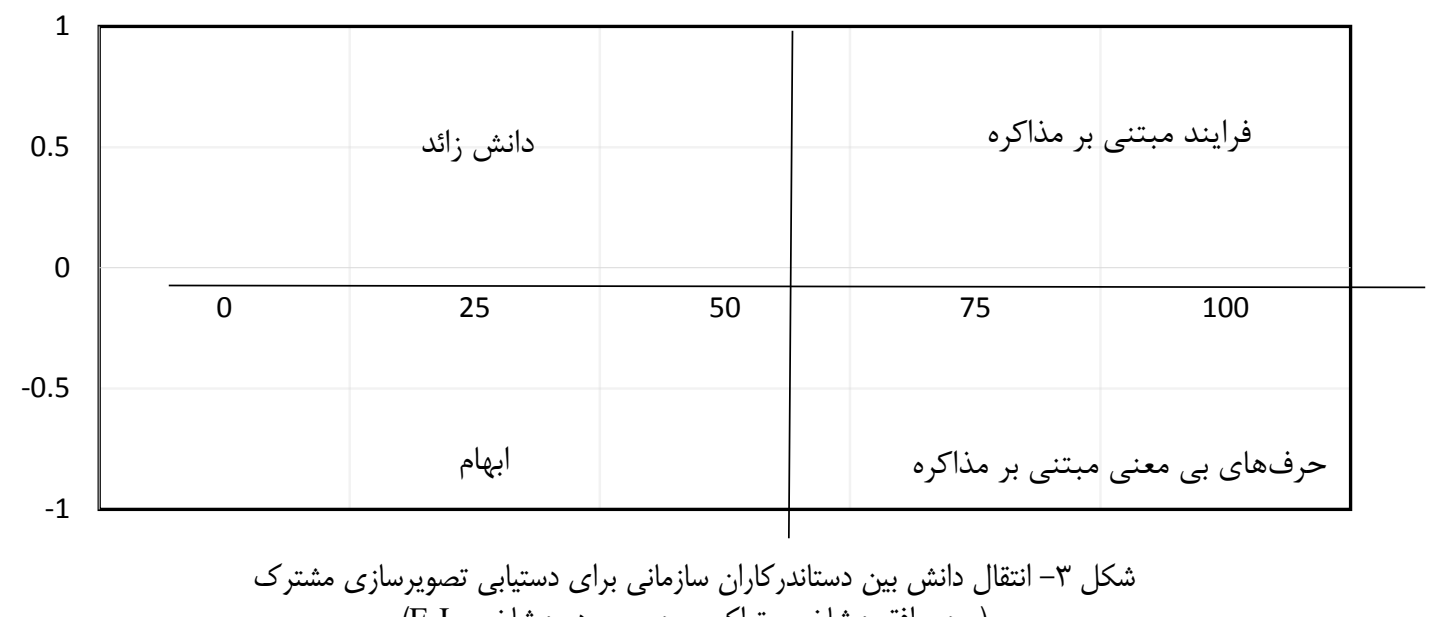

Figure 3. transfer of knowledge between organizational entities to obtain shared visualization (horizontal axis: density index, vertical axis: index E-I)

طرفى بر اساس مصاحبه مستقيم با كارشناسان ارشد

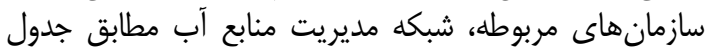

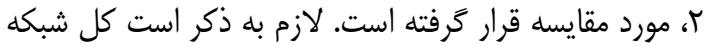

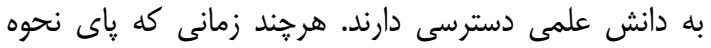

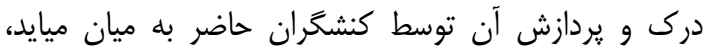

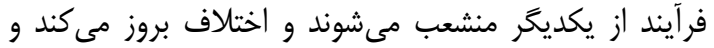

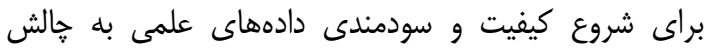

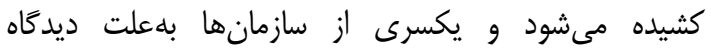

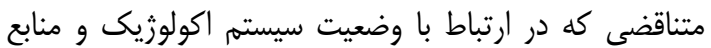

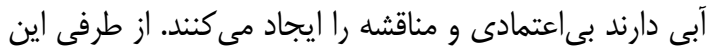

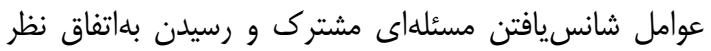

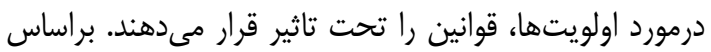

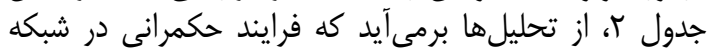

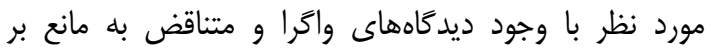
مىخورد.
نتايج و بحث

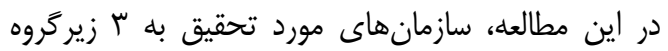

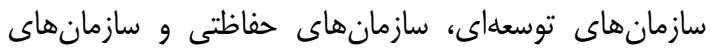

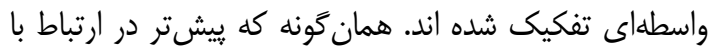

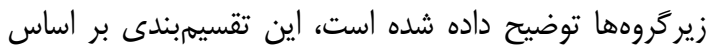

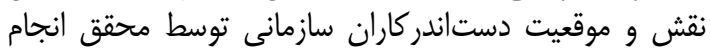

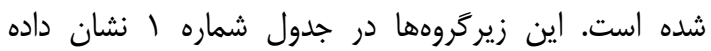

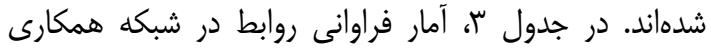

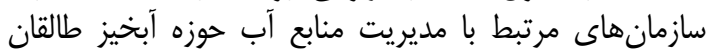

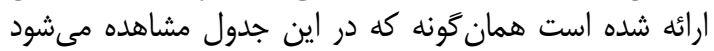

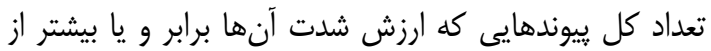

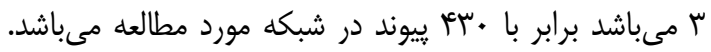

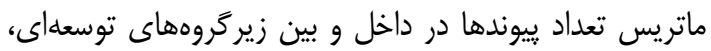

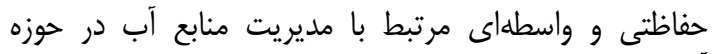
آبخيز طالقان در جدول شماره أل، نشان داده شده است. از ازيت إن 
Table 2. The joint visualization process in management

$$
\text { جدول r- فرآيند تصويرسازى مشترى در مديريت }
$$
شبكه دستاندر كاران سازمانى

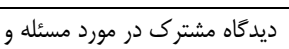

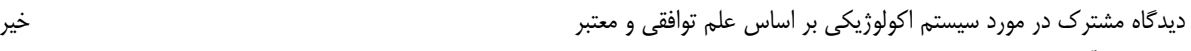

ابهام شاخص فرآيند شبكهسازى در مردي

جدول س- آمار فراوانى شدت روابط در شبكه همكارى سازمانهاى مرتبط با مديريت منابع آب حوزه آبخيز طالقان Table 3. Statistics of the intensity of relations in the network of organizations associated with the management of the water resources of Taleghan watershed

\begin{tabular}{|c|c|c|c|}
\hline جمع ييوندها & تعداد بيوندها & ارزش ييوند & سطح همكارى \\
\hline & Ft & $\cdot$ & بدون همكارى و روابط تعريف شده \\
\hline \multirow[t]{3}{*}{ קTr } & 90 & 1 & همكارى محدود پاسخ به استعلامات \\
\hline & 119 & r & همكارى از طريق عضويت در كاركروههاى مشترى \\
\hline & irv & r & همكارى از طريق تعريف تفاهمنامههاى مشترى \\
\hline \multirow[t]{2}{*}{ re. } & 191 & f & همكارى از طريق مشاركت در بروزهها \\
\hline & 90 & $\Delta$ & همكارى از طريق تبادلات مالى در يروزمهاى مشترى \\
\hline VQS & & & تعداد كل ييوندها \\
\hline
\end{tabular}

جدول ع- ماتريس تعداد يِوندها در داخل و بين زيرگروههاى توسعاى، حفاظتى و واسطهاى مرتبط با مديريت منابع آب در حوزه آبخيز طالقان Table 4. Matrix The number of links within and between developmental, protective and interface subgroups related to water resources management in Taleghan watershed

\begin{tabular}{|c|c|c|c|}
\hline 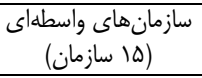 & 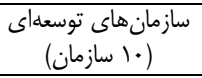 & 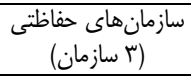 & \\
\hline rr & r & $r$ & سازمانهاى حفاظتى \\
\hline$\wedge V$ & $\Delta \Delta$ & 19 & سازمانهاى توسعهاى \\
\hline$\wedge \varepsilon$ & 94 & זr & سازمان هاى واسطةهاى \\
\hline
\end{tabular}

Table 5. Structural Quality of the Management Network

جدول ه- كيفيت ساختارى شبكه مديريت

\begin{tabular}{|c|c|}
\hline شبكه دستاندر كاران سازمانى & ويثزى هاى ساختارى \\
\hline$\Delta \cdot / \Lambda$. & تراكم \\
\hline rs & اندازه \\
\hline 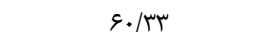 & تمركز درجه (\%) \\
\hline$\varphi \varphi / V$ & تمركز بينابينى (٪) \\
\hline$r q / v$. & تبادل فرابخشى (بر اساس شاخص E-I) \\
\hline قايين & ميزان بستهبودن (بر اساس شاخص تراكم) \\
\hline 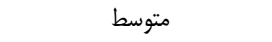 & يُّلدن (بر اساس شاخص E-I) \\
\hline
\end{tabular}

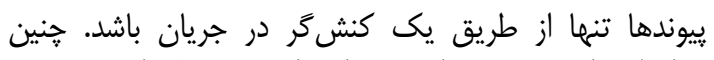

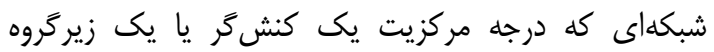

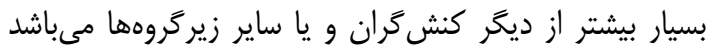

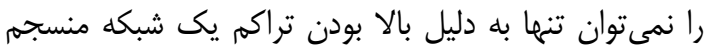

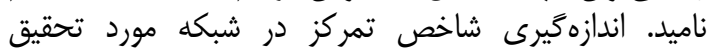

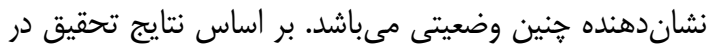

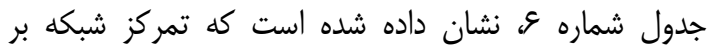

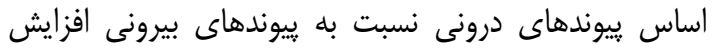

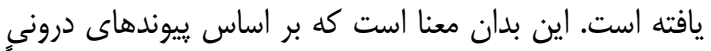

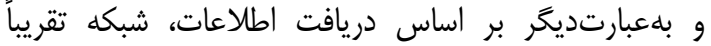

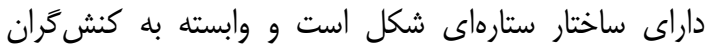

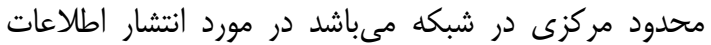

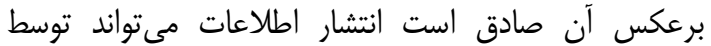
سازمانهاى بيشترى در اين شبكه انجام شود.

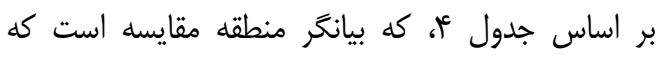

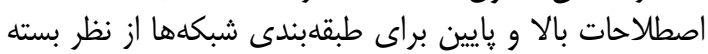

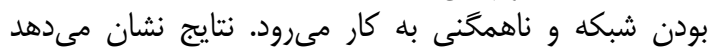

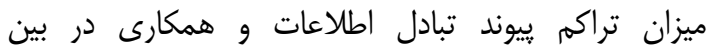

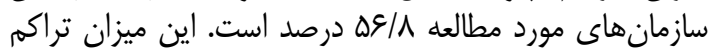

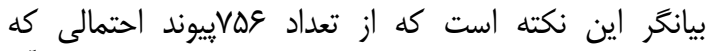

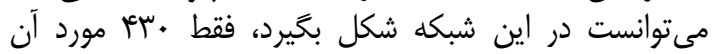

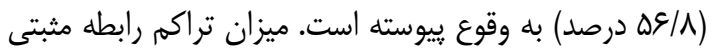

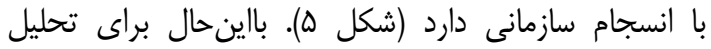

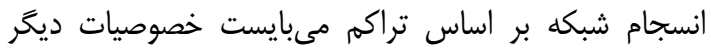

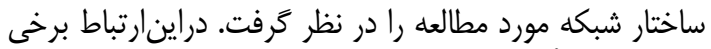

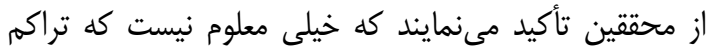

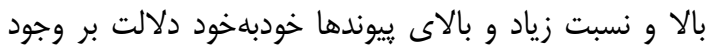

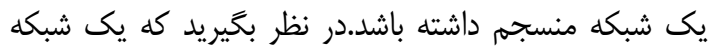

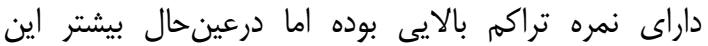


جدول צ- ميزان شاخص تراكم شبكه بر اساس بيوندهاى درونى و بيرونى در ييوند تبادل اطلاعات و همكارى Table 6. The network density index is based on internal and external links in the link of information exchange and collaboration

\begin{tabular}{|c|c|c|c|}
\hline مركزيت شبكه كل بر اساس ييوندهاى & مركزيت شبكه كل بر اساس ييوندهاى & نوع ييوند & مرز اكولوزيك \\
\hline$\mu \varphi / V$ & $9 \cdot / \pi$ & تبادل اطلاعات و همكارى & حوزه آبخيز طالقان \\
\hline
\end{tabular}

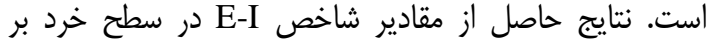

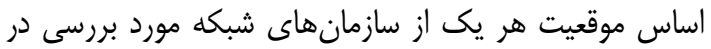

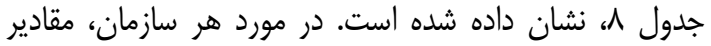

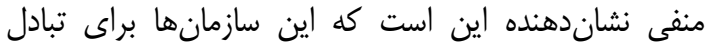

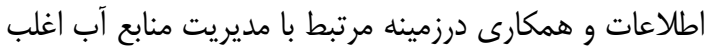

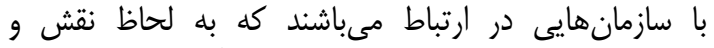

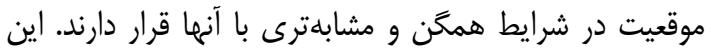

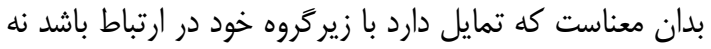

$$
\text { ساير زيرگروهها. }
$$

بر اساس نتايج حاصل از تحليل شاخصها نهاى تراكم و

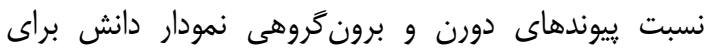

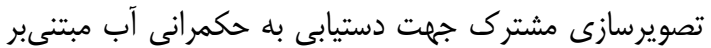

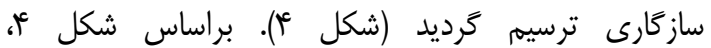

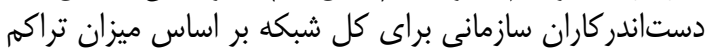

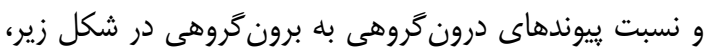
نشان داده شده است.
لذا با تقويت انسجام سازمانى مىتوان تصميمثيرى

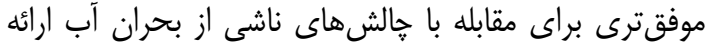

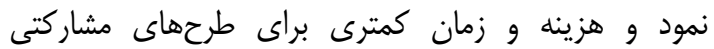

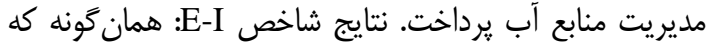

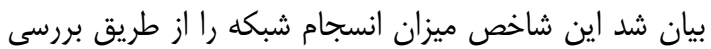

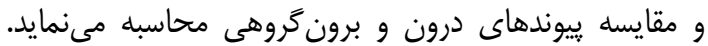

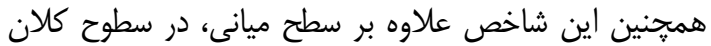

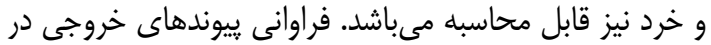

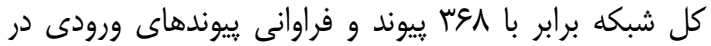

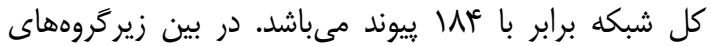

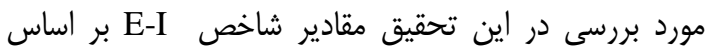

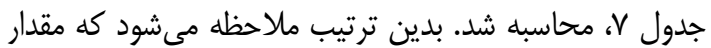

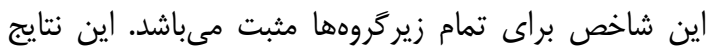

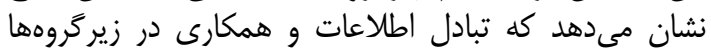

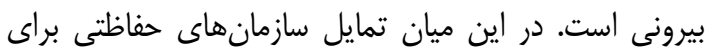

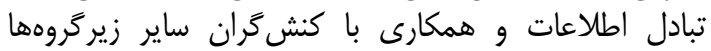

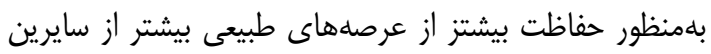

Table 7. The values of the index E - I are discussed among the subgroups investigated

\begin{tabular}{|c|c|c|c|c|}
\hline خروجى & ورودى & جمع & E-I مقدار شاخص & نام زيرگروه \\
\hline 11 & $\Delta \wedge$ & ve &.$- / 1 T$ & سازمان هاى حفاظتى \\
\hline$|f|$ & 99 & $r \cdot v$ & ع (r/. & سازمانهاى توسعهاى \\
\hline $1 Q V$ & $11 T$ & req &.$/ 19$ & سازمان هاى واسطهاى \\
\hline
\end{tabular}

Table 8. Results of the index E - I on the level of actors

جدول ^- نتايج شاخص E-I در سطح كنشگران

\begin{tabular}{|c|c|c|c|c|c|}
\hline ورودى لمى & 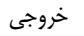 & جمع ( جم & E-I & ن ن ام سازمان & رديف \\
\hline r & r. & re & $-* / r$. & اداره منابع آب طالقان & 1 \\
\hline 9 & 19 & ra &.$- / T V$ & اداره منابع طبيعى و آبخيزدارى شهرستان طالقان & r \\
\hline$\Delta$ & tr & rv &.$- / F V$ & اداره حفاظت محيط زيست شهرستان طالقان & r \\
\hline 9 & $M$ & tr & 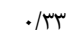 & فرماندارى شهرستان طالقان & f \\
\hline 9 & $M$ & tr & 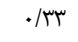 & مديريت جهاد كشاورزى شهرستان طالقان & $\Delta$ \\
\hline 8 & 14 & re & $\cdot / \Delta$ & شبكه بهداشت و درمان شهرستان طالقان & 8 \\
\hline द & 15 & $r$. & $\cdot / 4$ & مركز بهداشت شهرستان طالقان & $v$ \\
\hline ir & ri & ra & .1 .4 & بخشدارى مركزى طالقان & $\wedge$ \\
\hline f & r & $\checkmark$ &.$- / 14$ & اداره صنعت، معلن و تجارت شهرستان طالقان & 9 \\
\hline 8 & $\Delta$ & 11 & -.1 .9 & شهردارى طالقان & 1. \\
\hline 8 & $M$ & re & $\cdot / \Delta$ & اداره داميزشكى شهر ستان طالقان & 11 \\
\hline$\checkmark$ & M & ro & $\cdot / 4 F$ & امور آب و فاضلاب روستايى شهرستان طالقان & rו \\
\hline 14 & ז & rr &.$- / . r$ & بخش دارى بالا طالقان & if \\
\hline 9 & $M$ & tr & 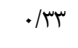 & شوراى اسلامى شهرستان طالقان & 10 \\
\hline$\checkmark$ & 1. & iv &.$/ / V$ & دهيارى جوستان بالا طالقان & 19 \\
\hline$\checkmark$ & 11 & 11 & $\cdot / 4 t$ & دهيارى مهران بالا طالقان & iv \\
\hline 9 & 1. & 19 & $.1 \cdot 0$ & دهيارى خيكان بالا طالقان & i1 \\
\hline v & 11 & ओ & $\cdot / 4 t$ & دهيارى ناريان بالا طالقان & 19 \\
\hline$\Delta$ & 11 & 19 & $\cdot / \mathrm{rV}$ & دهيارى كته ده بالا طالقان & r. \\
\hline
\end{tabular}


Continue Table 8. Results of the index E-I on the level of actors

ادامه جدول ^-نتايج شاخص E-I در سطح كنشخران

\begin{tabular}{|c|c|c|c|c|c|}
\hline ورودى & خروجى & جمع & E-I & 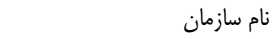 & رديف \\
\hline$\checkmark$ & 9 & 19 &.$/ 14$ & دهيارى حسن جون ميان طالقان & rI \\
\hline$\checkmark$ & 9 & 19 &.$/ 14$ & دهيارى خسبان ميان طالقان & זr \\
\hline 9 & 9 & M & · & دهيارى وشته ميان طالقان & Mr \\
\hline$\Delta$ & 11 & 19 & $\cdot / T V$ & دهيارى كش پايين طالقان & TV \\
\hline f & 1. & if &.$/ 4 t$ & دهيارى كجيران پايين طالقان & rA \\
\hline
\end{tabular}

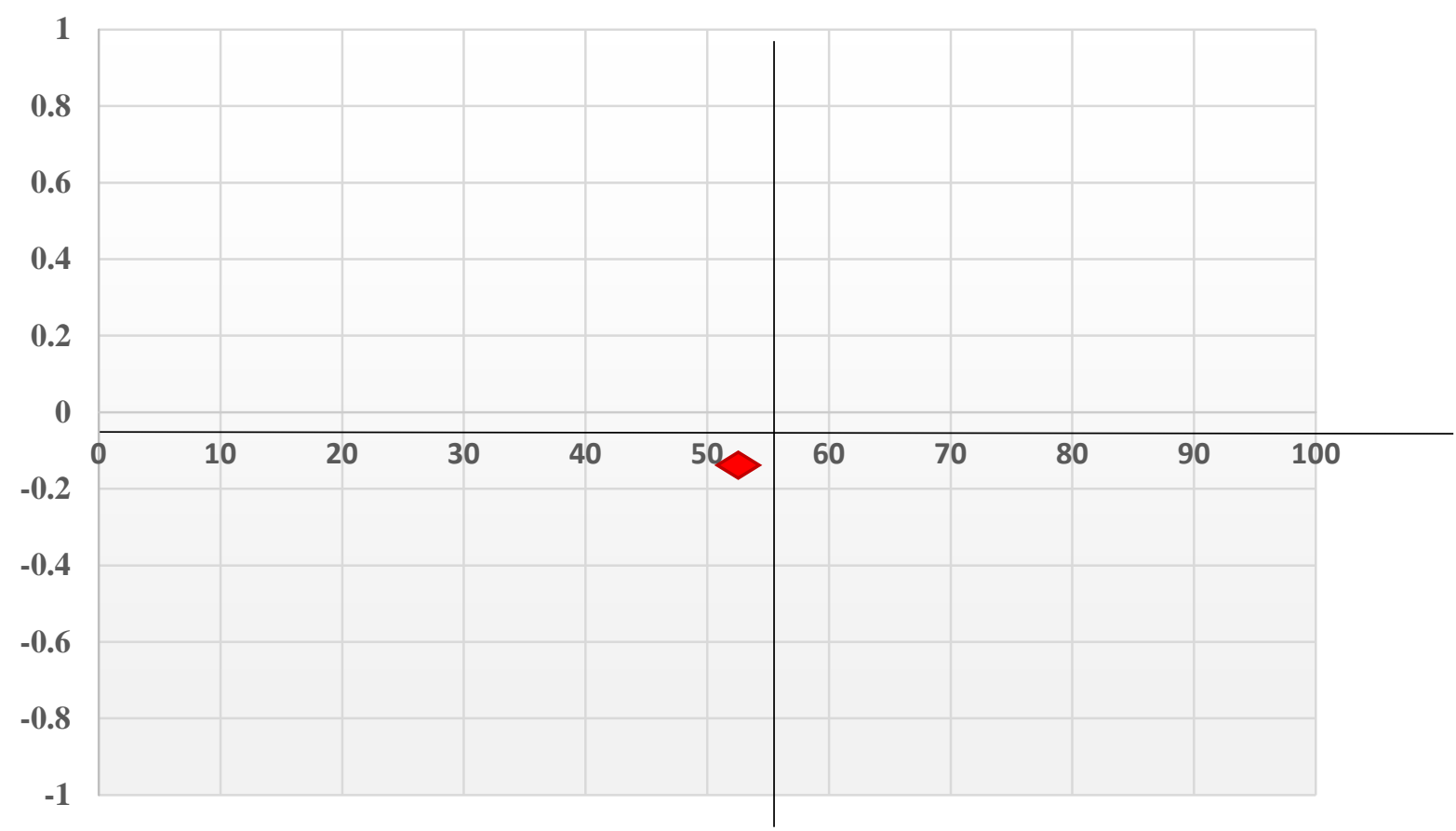

شكل ع- تصوير سازى مشترك دستاندر كاران سازمانى حكمرانى آب . Shover

Figure 4. Shared corporate relationships of water governance

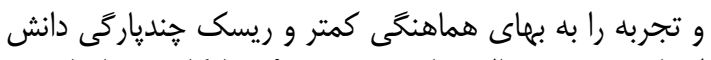

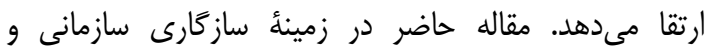

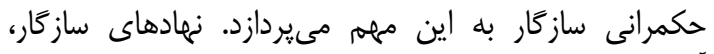

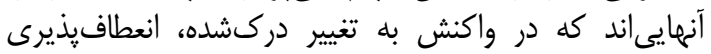

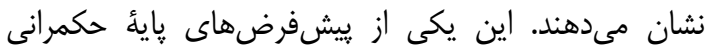

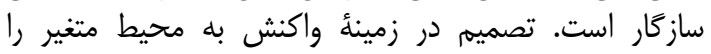

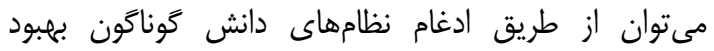

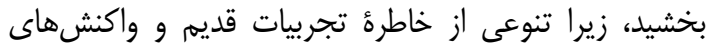

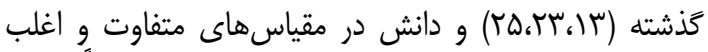

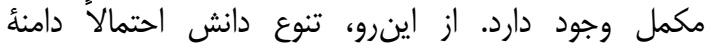

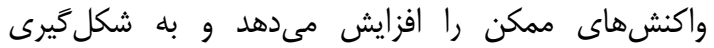

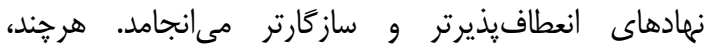

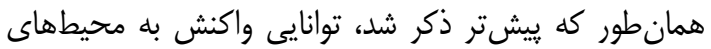

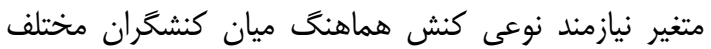

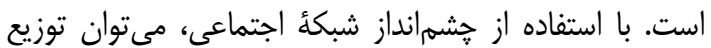

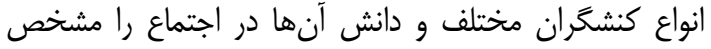

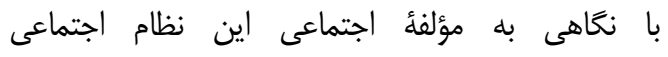

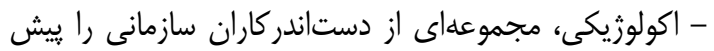

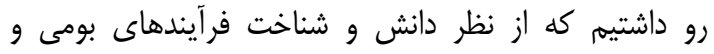

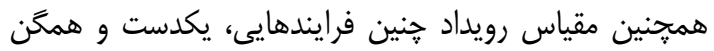

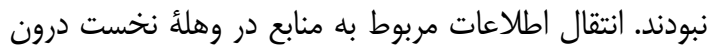

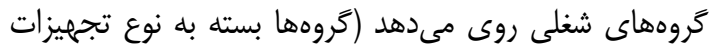

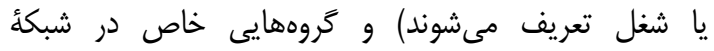

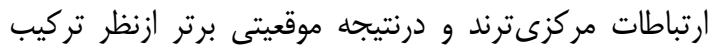

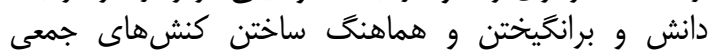

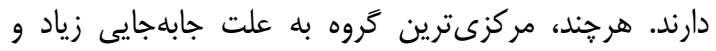

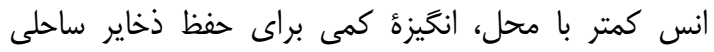

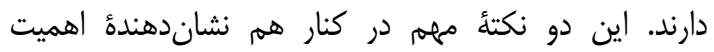

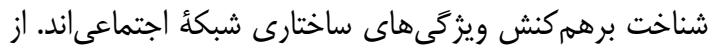

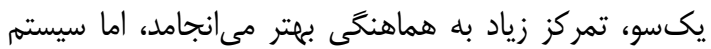

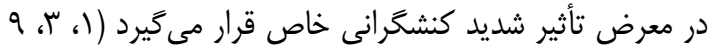

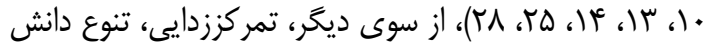




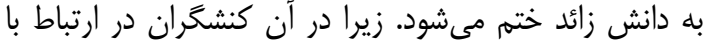

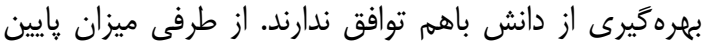

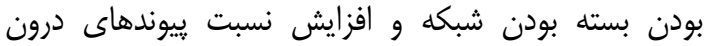

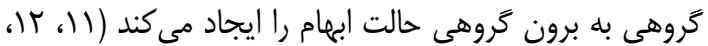

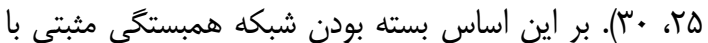

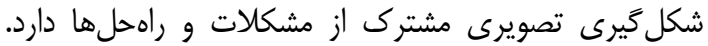

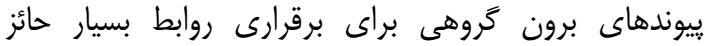

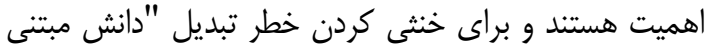

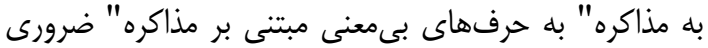

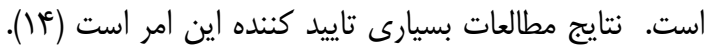

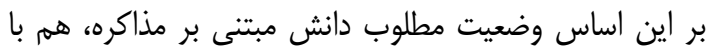

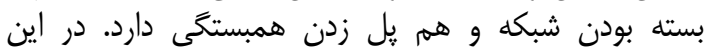

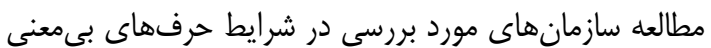

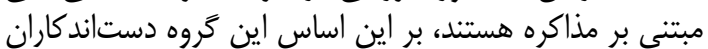

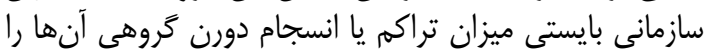

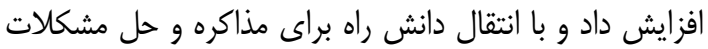

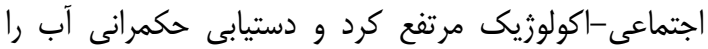

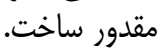

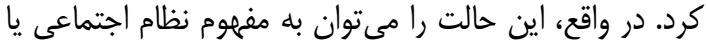

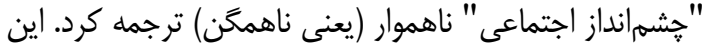

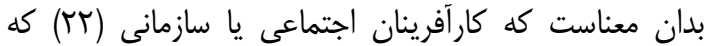

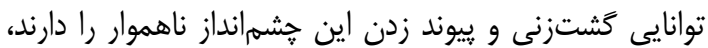

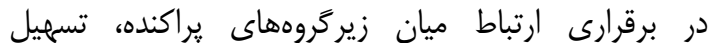

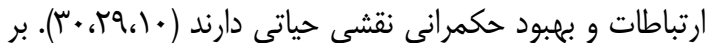

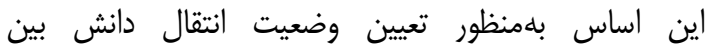

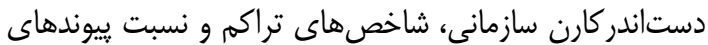

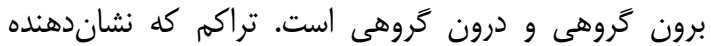

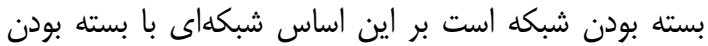

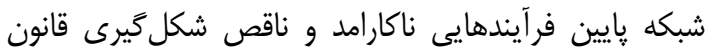

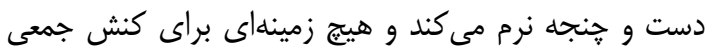

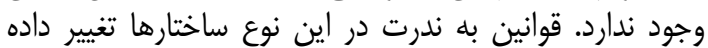

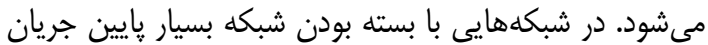

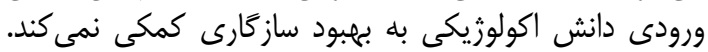

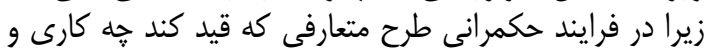

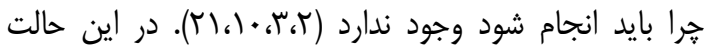
به جاى ايجاد دانش مبتنى بر مذاكره ورودى دانش درد در نهايت درايت

1. Bodin, Ö., B. Crona and H. Ernstson. 2006. Social networks in natural resource management: what is there to learn from a structural perspective. Ecology and Society, 11(2): 2.

2. Borgatti, S.P., M.G. Everett and L.C. Freeman. 2002. Ucinet for Windows: Software for social network analysis.

3. Bressers, H., D.B.C. Lordkipanidze, M. Özerol, G. Vinke-de Kruijf, J. Furusho, C. Lajeunesse, I. Larrue, C. Ramos, M.H. Kampa, E. Stein, U. Tröltzsch, J. Vidaurre and R. Browne. 2013. Water Governance Assessment Tool With an Elaboration for Drought Resilience. Drop project EU, 42 pp.

4. Bressers, H.K.S. 2013. Water governance regimes: Dimensions and dynamics. International Journal of Water Governance, 1(1-2): 133-156.

5. Brugha, R. and Z. Varvasovszky. 2000. Stakeholder analysis: a review. Health policy and planning, 15(3): 239-246.

6. Bunge, M. 2000. Ten modes of individualism - none of which works - and their alternatives. Philosophy of the social sciences, 30(3): 384-406.

7. Clarissa, R., D. Banzon-Cabanilla, R. Ancog and E. Peralta. 2017. Understanding water pollution management: Evidence and insights from incorporating cultural theory in social network analysis. Global Environmental Change, 45: 183-193.

8. Clarkson, M.E. 1995. A stakeholder framework for analyzing and evaluating corporate social performance. Academy of Management Review, 20(1): 92-117.

9. Dado, M.D. and A. Bodemer. 2017. review of methodological applications of social network analysis in computer-supported collaborative learning. ." Educational Research Review, 22: 159-180.

10. Ebrahimiazarkhran, F., M. Ghorbani, A. Malekian and H. Bressers. 2018. The analysis of social relations of water resources beneficiaries networks toward water resources co-management and adaptation in the face of the effects of climate change (Case study: Iran, Taleghan watershed). Climate change and water, France.

11. Ernstson, H. and S. Sörlin. 2009. Weaving protective stories: connective practices to articulate holistic values in the Stockholm National Urban Park. Environment and planning A, 41(6): 14601479.

ational project: Social network analysis; modeling, policy-making and implementation of natural resources co-management. University of Tehran, (In Persion).

12. Ghorbani, M. 2015. Iranian Pattern of Collaboration and Environment of Local Communities With the approach of Social Network, Department of Natural Resources, University of Tehran, (In Persion).

13. Ghorbani, M. and V. Jafarian. 2017. Social network analysis and natural resources mangemant. University of Tehran, (In Persion).

14. Ghorbani, M. and H. Moradi. 2013. "Social and policy networks in water governance." First International Symposium on Urban Development, 329-332. 
r. شبكه اجتماعى، تصويرسازى مشترك و ساز كارى در راستاى حكمرانى آب

15. Hare, M. and C. Pahl-Wostl. 2002. Stakeholder categorisation in participatory integrated assessment processes Integrated Assessment, 3(1): 50-62.

16. Hipel, K.W., D.M. Kilgour and R.A. Kinsara. 2014. Strategic investigations of water conflicts in the middle east. Group Decision and Negotiation, 23(3): 355-376.

17. Hornborg, A. 2009. Zero-sum world challenges in conceptualizing environmental load displacement and ecologically unequal exchange in the world-system. International Journal of Comparative Sociology, 50(3-4): 237-262.

18. Koontz, T.M. and C.W. Thomas. 2006. What do we know and need to know about the environmental outcomes of collaborative management? Public administration review, 66: 111-121.

19. Krott, M. and N.D. Hasanagas. 2006. Measuring bridges between sectors: Causative evaluation of cross-sectorality. Forest Policy and Economics, 8(5): 555-563.

20. Maas, A. 2011. Water, Governance and Sustainability: A Case Study of Water Allocation in Whiteman's Creek, Ontario (Master's thesis, University of Waterloo).

21. Maguire, S., C. Hardy and T.B. Lawrence. 2004. Institutional entrepreneurship in emerging fields: HIV/AIDS treatment advocacy in Canada. Academy of Management Journal, 47(5): 657-679.

22. Ostrom, E. 2005. Understanding Institutional Diversity . Princeton, NJ: Princeton University Press,

23. Pahl-Wostl, C., M. Craps, A. Dewulf, E. Mostert, D. Tabara and T. Taillieu. 2007. Social learning and water resources management. Ecology and society, 12(2).

24. Prell, C., K. Hubacek and M. Reed. 2009. Stakeholder analysis and social network analysis in natural resource management. Society and Natural Resources, 22(6): 501-518.

25. Sandström, A. 2011. Social networks, Joint image building and adaptability: the case of local fishery management.

26. Stringer, L., A. Dougill, E. Fraser, K. Hubacek, C. Prell and M. Reed. 2006. Unpacking "participation" in the adaptive management of social-ecological systems: a critical review. Ecology and society, 11(2).

27. Woolcock, M. 1998. Social capital and economic development: Toward a theoretical synthesis and policy framework. Theory and society, 27(2): 151-208.

28. Wossen, T. 2013. Social network effects on the adoption of sustainable natural resource management practices in Ethiopia. International Journal of Sustainable Development and World Ecology, 20(6): 477-483.

29. Yavuz, F.A.B. 2013. Use of swot and analytic hierarchy process integration as a participatory decision making tool in watershed management." Journal of Procedia Technology, 134-143. 


\title{
Social Network, Joint Image Building and Adaptation toward Water Governance (Case Study: Taleghan Watershed)
}

\section{Fariba Ebrahimiazarkhran ${ }^{1}$, Mehdi Ghorbani' ${ }^{2}$, Arash Malekian², Ali Salejegheh ${ }^{3}$, Amir Alambeigi ${ }^{4}$ and Hedayat Fahmi $^{5}$}

2- Associate Professor, University of Tehran, Iran, (Corresponding Author: mehghorbani@ut.ac.ir)

3- Professor, University of Tehran, Iran

4- Assistant Professor, University of Tehran

5- Deputy of Water and Waste Water Macro Planning Bureau of Ministry of Energy Received: July 31, $2018 \quad$ Accepted: November 21, 2018

\begin{abstract}
There is a multifaceted approach of water resource in a watershed, accompanied by complexity and issues such as the interaction of natural and human systems. Achieving the consistent governance of water resources is one of the most important management approaches in the water sector, which requires a coherent structure of knowledge transfer and information on the organizations stakeholders' network associated with water resources. In this research has been studied in Taleghan watershed to measure cooperation relations (transfer of water resources management knowledge), between 28 organizational practitioners (Including development, protective, and mediation organizations). In this study data were collected based on the questionnaire analysis. The results show that the knowledge structure of water resources management in Taleghan watershed is highly integrated among organizational stakeholders and the type of knowledge management is currently not based on negotiation. On this basis, it can be claimed that based on the bonding social capital index (relationships of each of the subgroups) is modest and based on the E-I index, bridging relations (relations between different subgroups) have a weak rate. It can be concluded that the relationship between water resource management and water resources management in Taleghan district level is an essential step to establish a cooperative governance of water resources.
\end{abstract}

Keywords: Adaptability, Joint image building, Organizational Stakeholders, Taleghan, Water Governance 